\title{
LENGUAS VERNACULAS Y TUTELA JUDICIAL EFECTIVA
}

\author{
(Comentario a la Sentencia del Tribunal Constitucional de 25 de \\ mayo de 1987)
}

\section{por}

Javier de la Oliva

1. La Sentencia de 25 de mayo de 1987 (1) no merecería una especial atención en estas páginas si no fuera porque, en su momento, obtuvo los honores de las primeras páginas de algunos periódicos y suscitó un pequeño cúmulo de opiniones. Sucede, además, que la Sentencia afecta al uso de las lenguas vernáculas y éste es un tema sobre el que siguen produciéndose importantes estudios (2): no parece que esté agotado o pacificado.

2. La Sentencia reconoce el «derecho a ser asistido por intérprete a los ciudadanos que no comprendan o no hablen el cas-

(1) En adelante, STC 74/1987. Se publicó en el «Boletín Oficial del Estado» el 9 de junio de 1987.

(2) Los más recientes: Guaita-Martoreul, Sobre el artículo 3.० de la Constitución: la enseñanza en las demás lenguas de España (Discurso de apertura del curso académico 1987-1988, en la Universidad Autónoma de Madrid), pág. 44; BAÑo LEÓN, «El ejercicio del pluralismo lingüístico en la Administración Pública», en Civitas, nú-

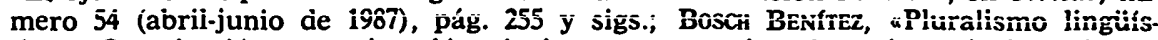
tico y Constitución: aproximación técnica y comentario a la reciente jurisprudencia constitucional», en Poder Judicial, núm. 7 (septiembre de 1987), pág. 55 y sigs.; FerNANDEZ ESPINAR, aLa doctrina constitucional sobre el multilingüismon, también en Poder Judicial, núm. 7 (septiembre de 1987), pág. 79 y sigs.

Una exposición completa de la jurisprudencia del Tribunal Constitucional sobre bilingüismo puede verse en Jurisprudencia constitucional en materia de autonomias territoriales. Año 1986, publicación del Ministerio para las Administraciones Públicas.

Especial mención requiere la monografía de Tolivar ALAS, L., Las libertades lingüisticas, INAP, 1987, 251 págs.: es el trabajo más extenso de los realizados recientemente. 
tellano", según dice literalmente el Fallo. Esto que prima facie aparece como elemental, ha sido reprochado con diversos argumentos que, en síntesis, pueden agruparse en tres bloques:

a) El Fallo - se dice- es contrario al artículo $30^{\circ}-1$ de la Constitución en cuanto este artículo impone el deber de conocer la lengua castellana. Rotundamente a favor de esta tesis se expresaba un comentario editorial del periódico Diario 16 (3), para quien "lo más preocupante es la carencia de fundamentación jurídica sólida» de la Sentencia. Sin esta virulencia y con moderación Villar Palasf afirma que «la doctrina (de la Sentencia) es impecable en cuanto al derecho de defensa, pero como hecho es un caso raro. Lo que se defiende es que no quieran hablar el castellano y consagra el derecho a no hablar en este idioma. Esto me parece muy discutible $y$ no es constitucional" (4) (el subrayado es nuestro). En opinión de FERNÁNDEZ EsPINAR, acuando el Tribunal Constitucional analiza el alcance territorial del ejercicio de este derecho, modifica completamente la interpretación del artículo $30^{\circ}$ de la Constitución llevada a cabo hasta este momento" (5).

b) Casi necesariamente unido a lo anterior, se tacha a la Sentencia de contraria al principio de igualdad, según ha sido diseñado éste por el propio Tribunal en abundante jurisprudencia anterior. "No puede seriamente hablarse de atentado al principio de igualdad - dice González PÉrez- por el hecho de que, siendo incuestionable el derecho de un extranjero a que el Tribunal le facilite un intérprete, se niegue tal asistencia al español. Por lo que para que se infrinja el principio de igualdad es necesario tratar desigualmente situaciones iguales»(6).

FERNANDEZ ESPINAR expresa esto mismo de otro modo: no es aceptable, dice, que el Tribunal Constitucional apele al artículo 14 para equiparar situaciones diversas, puesto que diversos son, por un lado, los extranjeros que no tienen la obligación de hablar el castellano, y, de otros, los españoles, que sí lo tienen: «en consecuencia, al no haber identidad de supuestos de hecho no puede haber identidad en los efectos o consecuencias jurídicas" (7).

(3) Diario 16, 28 de mayo de 1987.

(4) Diario $A B C$, de 8 de junio de 1987.

(5) Ob. cit., pág. 108.

(6) Diario $A B C$, de 8 de junio de 1987.

(7) Ob. cit., pág. 109. 
Se pretende así rechazar una rotunda afirmación de la Sentencia: «La atribución de este derecho (el de intérprete) a los españoles que no conozcan suficientemente el castellano y no sólo a los extranjeros que se encuentren en ese caso debe ofrecer duda. Lo contrario supondría una flagrante discriminación prohibida por el artículo 14 de la Constitución" (Fundamento Jurídico 3.).

c) Finalmente, para los detractores de la Sentencia, ésta se separa, también, de la Jurisprudencia anterior sobre el alcance territorial del uso de la lengua vernácula. Según esta tesis, el derecho a ser asistido por el intérprete sólo podría ejercerse dentro del territorio de una Comunidad Autónoma bilingüe.

Desde otra perspectiva, totalmente opuesta a los argumentos anteriores, merece la pena destacar la opinión de MarTín PaLlín para quien «el deber de conocer el castellano es una obligación programática que obliga a los españoles en la misma medida que la Constitución de Cádiz exigía a todos los ciudadanos que fuesen justos y benéficos" (8).

3. Quizás lo más acertado que se ha dicho sobre esta Sentencia es que "no ha sido entendida por todos, ni siquiera por todos los juristas» (9).

Es cierto que la Sentencia afecta y trata sobre el uso de las lenguas vernáculas y el castellano. Es evidente, también, que en sus Fundamentos Jurídicos se habla del principio de igualdad, de la territorialidad y del artículo $30^{\circ}-1$ de la Constitución. Sin embargo, y en esto consiste el cabal entendimiento de la Sentencia, ésta versa fundamentalmente $-\mathrm{y}$ por encima de cualquier otra consideración- sobre el derecho a la tutela efectiva; es decir, sobre el artículo 24 de la Constitución, no sobre el $3 .^{\circ}$ ni sobre el 14. El Tribunal monta toda su doctrina (muy acertadamente) desde el derecho reconocido en el artículo 24 y a partir de ahí su argumentación es impecable.

"La cuestión realmente planteada - dice el Fundamento Jurídico 2:- consiste, por tanto, en determinar si el ciudadano español... tiene, al igual que el extranjero, ... el derecho a ser asistido por intérprete cuando no comprende o habla el castellano". La respuesta es afirmativa porque la asistencia de intérprete

(8) Diario El Pais, 17 de junio de 1987. Martín Pallín escribe su trabajo periodístico en su condición de Presidente de la Asociación Pro Derechos Humanos.

(9) Guaita, ob. cit., pág. 42. 
"debe entenderse comprendida en el artículo 24.1 de la Constitución en cuanto dispone que en ningún caso puede producirse indefensión» (Fundamento Jurídico 3.॰).

Por supuesto que el Tribunal es consciente del deber que impone el artículo $30^{\circ}-1$ de la Constitución, pero aquí, en este caso, el deber cede «en cuanto afecta al ejercicio de un derecho fundamental cual es el de defensa» (Fundamento Jurídico 3.०). Es un gran acierto, en nuestra opinión, que el Tribunal ponga el derecho a la defensa muy por encima del deber de conocer la lengua; de otra forma estaríamos en presencia de una sutil y curiosa aplicación del principio "la letra con sangre entra" (al ignorante se le sanciona con indefensión y así aprenderá...). A fin de cuentas, la justicia - que incluye el derecho a la tutela- es un valor fundamental muy superior a la protección de la lengua. Por otro lado, impartir justicia y defender los derechos de los ciudadanos es obligación del Estado.

Es tan fuerte el derecho a la tutela efectiva que el Tribunal llega a decir -acertadamente- que el derecho a usar intérprete "deriva directamente de la Constitución y no exige para su ejercicio una configuración legislativa, aunque ésta pueda ser conveniente para su eficacia» (Fundamento Jurídico 4..$^{\circ}$ ).

Con estas premisas es obvio que la cuestión de la territorialidad es muy secundaria. El derecho a intérprete se tiene en cualquier punto de España... porque en cualquier punto de España rige el artículo 24.1 de la Constitución.

No se resiente el principio de igualdad -en nuestra opiniónporque el español que no puede defenderse en castellano es igual de ignorante, a estos efectos, que el extranjero. Lo que el Tribunal Constitucional denomina "juicio de igualdad» es una indagación sobre las razones de una diferenciación y su «justificación constitucional» (10). Y hay razones constitucionales suficientes (el dere-

(10) «El presupuesto esencial para proceder a un enjuiciamiento desde la perspectiva del art. 14 de la $\mathrm{CE}$ es que las situaciones subjetivas que quieran traerse a la comparación por el recurrente sean, efectivamente, cquiparables - Sentencia 76/1986, de 9 de junio-, y ello entraña la necesidad de que el término de comparación no resulte arbitrario o caprichoso; dicho en otras palabras, lo que se requicre para hacer posible un juicio de igualdad es que el legislador haya atribuido las consecuencias juridicas que se dicen diversificadoras a grupos o categorías personales creadas por él mismo, porque es entonces, si el autor de la norma diversifica lo homogéneo, cuando puede decirse también que su acción selectiva resulta susceptible de control constitucional dirigido a fiscalizar si la introducción de efactores diferenciales»-Sentencia $42 / 1986$, de 10 de abril- o de «elementos de diferencia- 
cho a la justicia) para no permitir que el español quede en situación de desigualdad frente al extranjero.

Este comentario quedaría incompleto si no se rechazara la reducción que propone Martín PallfN del deber previsto en el artículo $30^{\circ}-1$ a una declaración programática. La propia Sentencia dice que uel deber de los españoles de conocer el castellano hace suponer que ese conocimiento existe en la realidad, pero tal presunción puede quedar desvirtuada cuando el detenido o preso alega verosímilmente su ignorancia o conocimiento insuficiente o esta circunstancia se pone de manifiesto en el transcurso de las actuaciones policiales». Es decir, hay una presunción sobre el positivo conocimiento de la lengua; y la carga de la prueba recae en el "ignorante» o en la evidencia de los hechos. Acertadamente comenta Soriano que «bastará que el detenido o preso tenga bachiller elemental, por ejemplo, para que no quepa aduciones de desconocimiento del castellano...» (11).

Nada hay que añadir a esto excepto el recordar el Auto número 1.103/1986, de 17 de diciembre, en el que el Tribunal rechazó un recurso redactado en lengua vernácula. Con cierta ironía dice su Fundamento Jurídico único que «si el solicitante de amparo hubiera ofrecido alguna justa razón, demostrando su imposibilidad de comprender la lengua oficial del Estado (lo que en persona que invoca la condición de Abogado es altamente improbable), hubiera podido solicitar la habilitación de un intérprete según lo que previene el artículo 235.5 de la Ley Orgánica del Poder Judicial. No lo ha hecho así y, por consiguiente, su demanda debe ser inadmitida". Como se ve, la no utilización injustificada del castellano tiene consecuencias jurídicas.

En definitiva, no estamos en presencia de una Sentencia que se haya separado de la jurisprudencia anterior. La de 25 de mayo

ción» - Sentencia $162 / 1985$, de 29 de noviembre- resulta o no debidamente fundamînentauáa.

Donde tiene sentido preguntarse por la fundamentación en Derecho de una diferenciación normativa es, sobre todo, cuando la singularización entre categorías personales se realiza en la propia disposición, atribuyendo a las mismas regímenes jurídicos diversos, pues entonces es procedente indagar sobre las razones de la diferenciación y su justificación constitucional, en razón del fin perseguido por la norma y del criterio utilizado por el legislador para introducir diferencias en el seno del grupo sometido a un régimen jurídico común - Sentencias 22/1981, de 2 de julio; 34/1981, de 10 de noviembre, y 75/1983, de 2 de agosto- (STC 148/1986. Recurso de amparo 351/1985. Fund. Jur. 6).

(11) Diario $A B C$, de 8 de junio de 1987. 
de 1987 es una Sentencia sobre la tutela judicial efectiva en un caso de ignorancia de la lengua oficial; no al revés: no una Sentencia sobre el uso de la lengua vernácula o el castellano que afecta a la tutela judicial efectiva. 